\title{
Visión sobre docencia y cirugía actual
}

\author{
Teaching in surgery
}

Se me ha invitado, en mi calidad de decano de una facultad de medicina y miembro de nuestra sociedad de cirujanos, a reflexionar en relación a la docencia en cirugía y mi visión en relación a la cirugía actual; las que trataré de sintetizar a continuación desde mi perspectiva de Universidad regional.

La cirugía, en la actualidad, va evolucionando vertiginosamente con las diversas tecnologías aparecidas en sus distintas ramas, ya sea de la cirugía general, tanto laparoscópicas como endoscópicas, endovasculares, urológicas etc. Si bien esto, en general, es iniciado principalmente en Norte América o Europa; en nuestro medio sus primeras aplicaciones se dan en los principales centros quirúrgicos, especialmente de Santiago, ya sea en sus hospitales universitarios o en los centros privados con importantes recursos económicos.

En los hospitales regionales, por lo general, aunque sus médicos participen en diversas instancias formadoras, la aplicación de dichas nuevas tecnologías a menudo también sufre un desfase en el tiempo, principalmente debido a la escasez de recursos, espacios o de personal suficiente.

La creación de nuevas escuelas de medicina, si bien ha sido un punto de discusión y controversia tanto en el seno de ASOFAMECH como de las sociedades científicas y también entre los propios colegas, en relación a la sobrepoblación de profesionales que pudiese existir a nivel nacional así como de la calidad de los diversos procesos de formación involucrados, me ha llevado a la convicción de que para el desarrollo de nuestro país, ha sido un proceso crucial.

La alta migración de profesionales a la atención exclusivamente privada de la profesión médica, (donde el 52\% de nuestros médicos trabajan en forma exclusiva), ha hecho que el aporte de las universidades, especialmente regionales, así como de algunas privadas, sea fundamental en la mantención de estándares aceptables de atención a los usuarios de más escasos recursos y contribuir en la atención y potenciación de los hospitales en regiones. Pese a esto, sigue existiendo una gran desigualdad en la distribución de médicos a lo largo del territorio nacional con gran concentración en la zona central y un déficit prioritario, a nivel especialmente de la zona norte de nuestro país. La cirugía no es una excepción.

El déficit de especialistas sigue las mismas tendencias, con falencias importantes, en las zonas especialmente del norte del país así como de la Araucanía. Esto ha sido visualizado, tanto por los distintos gobiernos existentes como por el Colegio Médico y la ASOFAMECH. Es en este contexto, que el aporte que pueden hacer a nuestra especialidad las universidades creadas en regiones puede ser sustancial. No obstante, para poder cumplir tanto el rol formador en pre grado como a nivel de las especialidades médicas, es importante el trabajo conjunto y el aporte que pueden brindar las Universidades tradicionales y más antiguas con el fin de potenciar el desarrollo tanto de la cirugía como de otras especialidades a nivel regional.

No es fácil a este nivel desarrollar la especialidad de cirugía general o alguna sub especialidad quirúrgica, si no existe el capital humano suficiente para el desarrollo completo de la disciplina a entregar, y al mismo tiempo cumplir con los estándares necesarios para que este proceso formador pase los niveles exigidos para ser acreditados como programas de excelencia. De ahí que es muy importante, a fin de lograr una efectiva descentralización y desarrollo de las regiones, que los hospitales universitarios del nivel central sean generosos en apoyar la formación de especialidades médicas a nivel regional y de esta forma disminuir las brechas en salud tanto en cuanto a la distribución médica como también de especialistas.

El desarrollo de carreras de medicina lejos de la zona central, también ha permitido a través de diferentes convenios existentes, que becados de cirugía de Santiago puedan participar dentro de su proceso de formación de estadías en hospitales de regiones, lo que sin duda les ha permitido, por un lado, ampliar su horizonte 
EDITORIAL

al comprobar que en estos centros también se efectúa cirugía de alta complejidad aunque en volúmenes menores; por otro lado, ver la realidad propia que existe a nivel país, como asimismo, participar activamente en un alto número de cirugías tradicionales, que si existen en abundancia y que no siempre pueden efectuar con la frecuencia dada en los congestionados centro quirúrgicos centrales. Además los becados estimulan a los médicos de regiones, y especialmente de hospitales estatales, a cambiar un poco su rutina y cooperar en la formación de pos grado, así como también de capacitarse en las técnicas innovadoras a fin de poder contribuir plenamente a la formación de los becados que llegan a sus servicios. Esto mismo, aparejado a la irrupción de las escuelas de medicina regionales, ha permitido que se desarrolle por parte de estas universidades en regiones procesos de capacitación en metodologías de didáctica y enseñanza de los diversos profesionales que laboran en el área salud, que ha llevado a un rápido avance en adquirir por parte de ellos las capacidades para entregar una docencia de alta calidad y con estándares de excelencia, además de ser un estímulo para mejorar sus competencias, lo que sin duda han sido de gran beneficio para una mejor atención de los usuarios. De igual forma, la presencia de estos centros formadores estimula a estos becados a tener como una posibilidad cierta, después de completada su formación de especialista, el trabajar en regiones no sólo desarrollando su especialidad sino que también en la perspectiva de seguir una carrera docente.

Estoy convencido que se debe estimular la formación de cirujanos a nivel regional, con el decidido apoyo central (y también ministerial). Este estímulo incluso pudiese darse con estadías cortas de especialistas en la región respectiva donde puedan compartirse no sólo experiencias quirúrgicas, sino también docentes, con los cirujanos locales. Creo que sería un fuerte estímulo para disminuir las actuales brechas existentes y lograr una mayor equidad también en la entrega de salud a nuestra población.

Dr. Nicolás Velasco M. Servicio Cirugía Coquimbo Decano

Facultad de Medicina Universidad Católica del Norte 